\title{
ANÁLISE DE VIABILIDADE DA UTILIZAÇĀO DE CONCRETO COM ADITIVO DA PALMA FORRAGEIRA EM MUROS DE ARRIMO POR GRAVIDADE
}

\author{
ISIS DOS SANTOS COSTA \\ Estudante de graduação \\ Universidade Federal Rural do Semi-Árido \\ Rio Grande do Norte; Brasil \\ Isis.sj@hotmail.com
}

\author{
JOSÉ HENRIQUE MACIEL DE QUEIROZ \\ Engenheiro Civil (docente) \\ Universidade Federal Rural do Semi-Árido \\ Rio Grande do Norte; Brasil \\ henrique.jhmq@hotmail.com
}

\section{RESUMO}

A busca por insumos que possam aprimorar o desempenho do concreto, tem se tornado um hábito comum entre pesquisadores do setor da construção civil, com o inuito de diversificar a cadeia produtiva desta. Nesse sentido, os aditivos químicos, são largamente conhecidos pela sua eficiência de melhoria na qualidade do concreto em seus estados fresco e endurecido, porém, tratam-se de produtos onerosos, não acessíveis a todos. Sendo assim, buscou-se neste trabalho, estudar os efeitos da adição da mucilagem do cacto, popularmente conhecido como Palma Forrageira , em concretos, para verificação de viabilidade técnica do seu uso, em muros de arrimo por gravidade. Partiu-se do pressuposto que essa adição poderia produzir resultados semelhante a certos aditivos industrializados. Utilizou-se então, uma metodologia experimental, com moldagem de dezesseis corpos-de-prova cilíndricos (10 x $20 \mathrm{~cm})$, dos quais quatro foram produzidos insentos da mucilagem, e os demais aditivados em diferentes proporções $(0,5 \%$; $1 \%$; e $1,5 \%)$ do total da massa de seu material cimentício. Após o período de cura úmida dos concretos (28 dias), eles foram submetidos a ensaios de resistência axial à compressão, peso específico e absorção de água por capilaridade. Os resultados indicaram uma viabilidade parcial da utilização do aditivo do cacto em pó, uma vez que este aumentou em aproximadamente $9 \%$ a resistência a compressão do concreto e melhorou sua trabalhabilidade, pois gerou um material mais fluído e com maior tempo de pega que os concretos convencionais. Em contratpartida, o concreto com adição da mucilagem apresentou uma dimunição do peso específico, o que não é vantajoso para construção de muros de arrimo por gravidade, em virtude de seu princípio de estabilidade partir do seu elevado peso próprio. Os resultados do ensaio de absorção de água por capilidade foram inconclusivos, em virtude de uma aticipicidade nestes.

Palavras-chave: concreto, qualidade, aditivos, cacto, mucilagem.

\section{ABSTRACT}

The search for materials that can improve the performance of concrete, has become common among researchers in the construction sector, with the innumerous effort to diversify its production chain. In this sense, chemical additives are widely known for their efficiency in improving the quality of concrete in its fresh and hardened states, however, they are costly products, not accessible to everyone. Therefore, this work sought to study the effects of adding the mucilage of the cactus, popularly known as Palma Forrageira, in concrete, to verify the technical feasibility of its use, in retaining walls by gravity. It was assumed that this addition could produce results similar to certain industrialized additives. An experimental methodology was then used, with the molding of sixteen cylindrical specimens $(10 \mathrm{x} 20 \mathrm{~cm})$, of which four mucilage insects were produced, and the others were added in different proportions $(0.5 \% ; 1 \%$ and $1.5 \%)$ of the total mass of its cementitious material. After the period of wet curing of the concretes ( 28 days), they were subjected to tests of axial compressive strength, specific weight and water absorption by capillarity. The results indicated a partial viability of using the powdered cactus additive, since it increased the compressive strength of concrete by approximately $9 \%$ and improved its workability, as it generated a more fluid material and with a longer setting time than concretes conventional. In counterpart, concrete with the addition of mucilage showed a decrease in specific weight, which is not advantageous for the construction of retaining walls by gravity, due to its principle of stability starting from its high own weight. The results of the water absorption by capacity test were inconclusive, due to their atticity.

Keywords: concrete, quality, additions, cactus, mucilage.

\section{INTRODUÇÃO}

Estruturas de contenção de solos, compõem uma significativa área da engenharia geotécnica, uma vez que são responsáveis por garantir a segurança de obras da engenharia civil, como a construção de casas, prédios, estradas, 
pontes, entre outras. Consequentemente, asseguram também, as pessoas e a preservação do meio ambiente. Dessa forma, as estruturas de contenção devem garantir o equilíbrio de massas de solo (MATERA e ROMANEL, 2014).

Essas estruturas são quase sempre necessárias em obras de fundações, especialmente aquelas em que houve movimentação de terra. Sua utilização é constante em construções com criação de subsolos para estacionamento em residenciais, obras em que existiu cortes ou aterros e criação de plataformas. As contenções do terreno estão presentes em projetos de estradas, de pontes, de estabilização de encostas, de canalizações, de saneamento, de metrôs, entre outros (VARELA, 20-?).

Os tipos mais comuns destas estruturas são: muro de gravidade, cortina de prancha, cortina de prancha embutida, cortina de prancha ancorada, parede de embasamento, parede de estribo de ponte, parede de solo reforçado e muro de tirantes ancorados (MATERA e ROMANEL, 2014).

Os muros de gravidade, estrutura que será analisada neste trabalho, são assim chamados, pois de acordo com Kanappet e Craig (2016, p. 316) sua "estabilidade deve-se ao seu peso próprio, talvez auxiliado pela resistência passiva desenvolvida na frente da parte anterior da base ou do pé (chamado em inglês de toe, ou ponta) do muro". Estes muros geralmente são feitos de concreto, material de construção muito comum.

As propriedades e as características do concreto, irão depender das proporções e qualidade dos materiais que o compõe. O principal componente do concreto é o cimento, que por ser quimicamente mais ativo, tem a finalidade de unir os agregados e contribui para atingir a resistência final desejada (CABRAL e AZEVEDO, 2016). Nesse sentido, de acordo com Cabral e Azevedo (2016), existiu necessidade de melhorar algumas características do concreto, como a resistência, leveza, flexibilidade, custos, entre outras. Esse fato culminou no desenvolvimento de aditivos e incentiva a busca por outros tipos de materiais que, quando adicionados ao concreto, possam aprimorar seu desempenho.

Dessa forma, a família de cactáceas, espécie de plantas encontradas principalmente em locais áridos e semiáridos, surge como um possível material a ser adicionado no concreto para melhoria de suas propriedades. Inserida na família de cactáceas, a palma forrageira é rica em água e detém de baixa concentração de matéria seca, quando processada fornece uma mucilagem bastante espessa capaz de tornar-se um veículo de dispersão de materiais pulverulentos. Essa característica da mucilagem da palma é conhecidamente utilizada na pintura com cal (caiação) e na estabilização de construções com terra (OLIVEIRA, 2018).

Dessa maneira, encontrar novos insumos para compor a cadeia produtiva da construção civil, tem o propósito de gerar um progresso econômico integrado as necessidades do setor construtivo do país. Assim, estudar a introdução da mucilagem da palma forrageira, que funcionará como um aditivo, em concretos, para confecção de muros de arrimo por gravidade é uma possibilidade de contribuir para o desenvolvimento de tecnologias alternativas para o setor construtivo. Analisar a viabilidade desse material como aditivo para o concreto, a partir de um processo acessível, que se baseia na extração da mucilagem do cacto, foi o que incentivou essa pesquisa.

Portanto, essa pesquisa tem como objetivo estudar os efeitos da adição da mucilagem do cacto popularmente conhecido como Palma Forrageira, em concretos, para verificação de viabilidade deste em estruturas de contenção do tipo muro de arrimo por gravidade. Especificamente, extrair a mucilagem do cacto Palma Forrageira em forma de pó para ser incorporado ao concreto, produzir dezesseis corpos-de-prova, cilíndricos de dimensões 10 x $20 \mathrm{~cm}$, dos quais doze serão elaborados de concreto com a adição da mucilagem da Palma forrageira, e os outros quatro serão produzidos de concreto sem adição da mucilagem, e realizar ensaios de peso específico, absorção de água por capilaridade e resistência a compressão axial nos concretos produzidos.

\section{REFERENCIAL TEÓRICO}

\subsection{O concreto: suas classificações e propriedades}

Após a mistura dos materiais constituintes do concreto, este deve apresentar plasticidade suficiente para os procedimentos de manuseio, transporte e lançamento, ganhando resistência e coesão ao longo do tempo, em decorrência das reações entre a água e aglomerante. Pode ser adicionado aditivos ao concreto, com finalidade de modificar suas características físicas e químicas (ALMEIDA, 2002). 
Material constituinte do concreto mais importante, o cimento, de acordo com a definição presente na Norma 16697 é um "ligante hidráulico obtido pela moagem de clínquer Portland, ao qual se adiciona, durante a fabricação, a quantidade necessária de uma ou mais formas de sulfato de cálcio e adições minerais" (ASSOCIAÇÃO BRASILEIRA DE NORMAS TÉCNICAS, 2018, p.2).

Existem diversos tipos de cimento de cimento Portland, que variam a depender de suas propriedades e adições especiais. Eles são designados por suas respectivas siglas, seguidas de sua classe de resistência mínimas à compressão aos 28 dias de idade (25 Mpa, $32 \mathrm{Mpa}, 40 \mathrm{Mpa}$ ou Alta Resistência Inicial- ARI), acrescida dos sufixos RS (Resistente a sulfatos) e BC (Baixo Calor de hidratação) quando aplicáveis. ABNT NBR 16697:2018

Outro material constituinte do concreto são os agregados, materiais geralmente inertes, ou seja, que não reagem com o cimento, e tem a finalidade de reduzir a retração, aumentar a resistência e reduzir os custos do concreto (JÚNIOR, 20?). Os agregados com relação as suas dimensões se classificam entre miúdos e graúdos.

Por fim, a água também se faz presente na composição do concreto. As águas de origem natural são quase todas apropriadas para serem utilizadas no amassamento do concreto. Entende-se por fator água/cimento, o teor de água do concreto fresco, ou seja, a relação entre o peso da água e do cimento utilizados no traço do concreto. Geralmente essa relação tem valores girando entre 0,3 a 0,6 . Vale ressaltar que quanto menor o teor de água no concreto, maior será sua resistência e menor sua trabalhabilidade (ALMEIDA, 2002).

O concreto é classificado de diferentes maneiras, em relação a utilização ou não de armaduras, segundo seus diversos campos de aplicação, com relação ao seu peso específico, conforme sua resistência à compressão e de acordo com o fornecimento das centrais de concreto. A Figura 1 ilustra um processo simplificado para a classificação do concreto em relação as formas de uso das armaduras.

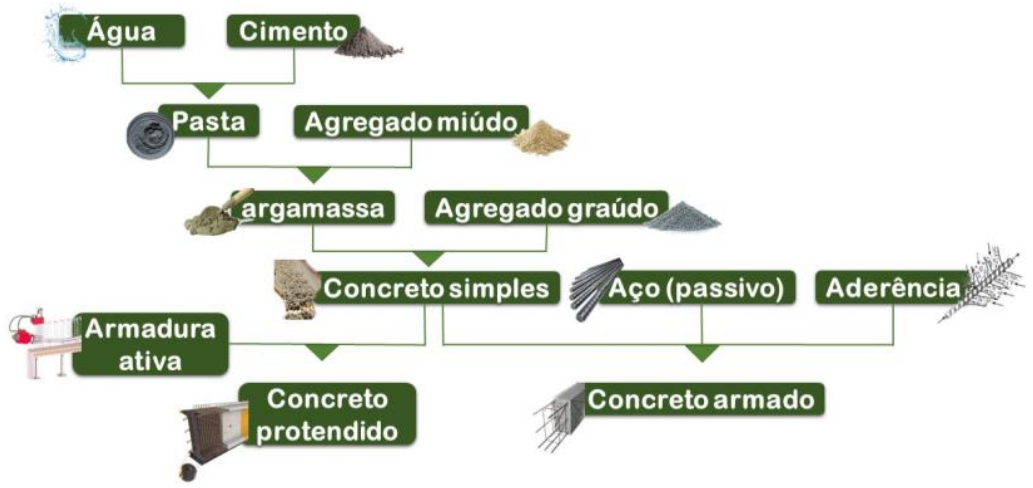

Figura 1: Classificação do concreto em relação a utilização da armadura

Fonte: os autores, 2019.

Com relação ao seu campo de aplicação, o concreto pode ser dito estrutural ou concreto massa. Entende-se por concreto massa todo volume de concreto com dimensões grandes, o suficiente para se tomar medidas a superar o alto calor de hidratação do cimento. Obras com a necessidade de utilizar grandes volumes de concreto massa na sua confecção tornam-se preocupantes, pois, estão mais sujeitas ao surgimento de patologias, tais como trincas e fissuras (AMERICAN CONCRETE INSTITUTE, 2005). O concreto estrutural é estabelecido como sendo um "termo que se refere ao espectro completo das aplicações do concreto como material estrutural" (ASSOCIAÇÃO BRASILEIRA DE NORMAS TÉCNICAS, NBR 6118, 2014, p. 3).

Em relação ao seu peso específico, o concreto pode ser do tipo normal (C), concreto leve (CL) e concreto pesado ou denso (CD). A Norma 8953 pauta que a depender da sua classe de resistência os concretos são classificados em dois grupos (I e II). Os concretos do Grupo I são aqueles com resistência característica a compressão entre 20 Mpa e 50 Mpa, já os do Grupo II são aqueles com resistências superiores a 55 Mpa (ASSOCIAÇÃO BRASILEIRA DE NORMAS TÉCNICAS, NBR 8953, 2015).

A consistência do concreto no estado fresco trata-se de uma propriedade interligada com a situação de fluidez da mistura. Ela se altera quase que unicamente com a quantidade de água utilizada no concreto, correspondendo a menor 
ou maior facilidade de se deformar sobre cargas. Um concreto com adequada consistência tem sua trabalhabilidade garantida (AMBROZEWICZ, 2012).

A exsudação no concreto está relacionada com a tendência de a água de amassamento surgir na superfície do concreto recentemente lançado, originando mais poros e consequentemente um concreto menos resistente. A segregação é a tendência dos agregados graúdos que compõem o concreto se separar da argamassa, resultando em um concreto sem homogeneidade, ou com muitos vazios, diminuindo a sua resistência mecânica (AMBROZEWICZ, 2012).

\subsection{Aditivos para concreto}

A Norma Brasileira 11768 define aditivo como sendo o produto adicionado durante o processo de preparação do concreto, em quantidade não maior que $5 \%$ da massa de material cimentício contida no concreto, com o objetivo de modificar propriedades do concreto no estado fresco e/ou no estado endurecido, exceto inorgânicos para o preparo de concreto colorido (ASSOCIAÇÃOBRASILEIRA DE NORMAS TÉCNICAS, NBR 11768, 2011).

O uso de aditivos ao concreto tem se tornado bastante comum nas obras civis, para Neville (2016), a razão para esse crescente uso está na capacidade destes em conferir consideráveis vantagens ao concreto. Esses benefícios compreende a utilização do concreto em situações na qual antes haviam dificuldades consideráveis ou mesmo insuperáveis, além de que a utilização de aditivos permite o uso de uma maior variedade de componentes na mistura.

\subsection{Estruturas de contenção: Muro de arrimo por gravidade}

Entende-se por estruturas de contenção toda obra da engenharia geotécnica que são executadas com o objetivo de dar estabilidade contra a ruptura de maciços de terra ou rocha. Existe uma diversidade de estruturas de contenção, dentre as quais, são mais comuns os chamados muros de arrimo, cortinas atirantadas, gabiões, estacas pranchas, muros em forma de cortina com perfis metálicos ou painéis pré-moldados (ANDRADADE ET. AL, 2003).

Para Andrade et. Al (2003, p. 37), os muros de arrimo são estruturas de contenção "corrida de parede vertical, apoiadas em uma fundação rasa ou profunda, podendo ser de vários tipos: gravidade (construídos de alvenaria, concreto, gabiões ou peneus), de flexão com ou sem contrafortes e tirantes”. A Figura 2 ilustra a terminologia dos componentes que constituem um muro de arrimo, que são: crista, corpo, tardoz, base e dente. Enquanto a Figura 3 demonstra os tipos mais comuns dos muros de contenção: muro de gravidade, gravidade armado, incado e ancorado.

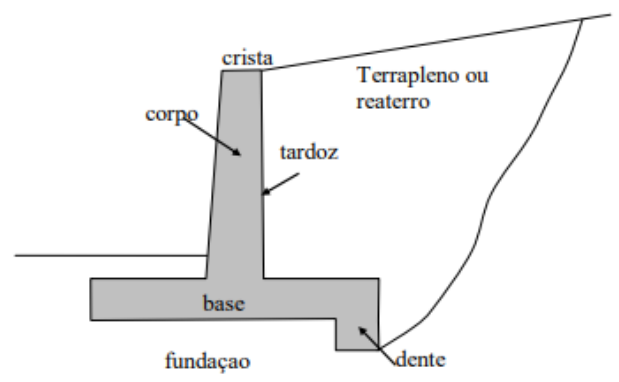

Figura 2: Terminologia dos componentes de um muro de arrimo Fonte: GERSCOVICH, (20-?).

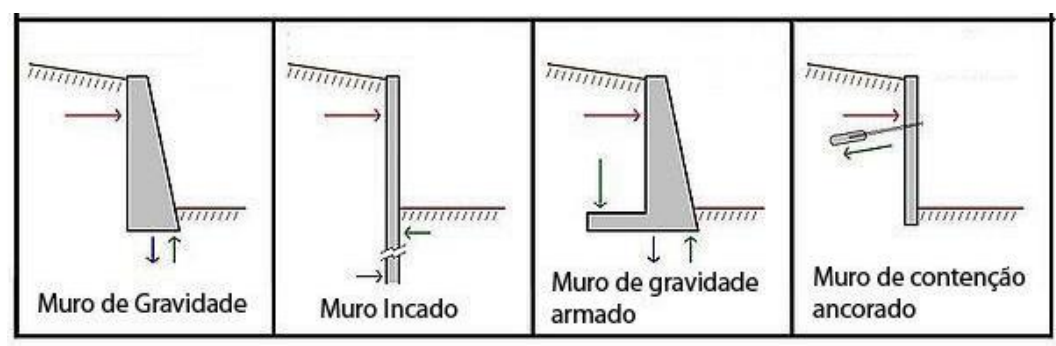

Figura 3: Principais tipos de muros de contenção VIVA DECORA, 2019. 
De acordo com o manual do projeto de muro de arrimo, emitido pelo Departamento de Estradas de Rodagem (DER, 2005), a geometria e a constituição do muro devem ser apropriadas, capazes de suportar as solicitações críticas durante a vida útil com a segurança desejada. O sistema estrutural é constituído por paramento e fundação, podendo haver elementos de reforço do maciço. Além dos elementos já elencados, costumeiramente os muros de arrimos são compostos de elementos drenantes e filtrantes, como filtros de areia ou brita, drenos profundos, barbacãs, drenos subhorizontais e canaletas (DER, 2005).

Os muros de arrimo por gravidade são estruturas de contenção corridas que se opões aos empuxos horizontais pela ação do seu peso próprio. Normalmente, são empregues para conter desníveis pequenos ou médios, inferiores a 5 metros. Os materiais utilizados para sua construção pode ser pedra, concreto (simples ou armado), gabiões, ou pneus usados (ANDRADADE ET. AL, 2003).

Essas obras de contenção contam com seu peso próprio e os esforços da base para manter sua estabilidade. Para sua construção é necessário um grande volume de material construtivo, e em virtude disto, sua aplicação é limitada pela capacidade de suporte do solo, geralmente sendo necessária uma capacidade mais elevada que para o restante dos tipos de muros. São muito utilizados em projetos de barragens, para conter aterros junto às estruturas hidráulicas, tais como vertedouro e tomada d'água (ARAÚJO, 2016).

\subsection{A Palma Forrageira e o seu uso na construção civil}

As mais relevantes espécies de plantas suculentas, caracterizadas por serem carnudas e ricas em água, sendo capazes de resistirem a grandes períodos de seca, são os chamados cactos, também conhecidos por cactáceas e cactaceae. A palavra cacto, do grego Kaktos, significa planta que tem espinhos. A utilização inicial de tal palavra foi dada pelos próprios gregos, em 300 anos a.C. (BALLESTER OLMOS, 1995, apud, COSTA, 2014).

No Nordeste Brasileiro ocorre a predominância de cactáceas dos gêneros Cereus, Opuntia e Pilosocereus, inseridos o Cereus jamacuro, Opuntia fícus-indica e Facheiro, popularmente conhecidos como Mandacaru, Palma e Facheiro, respectivamente. A palma forrageira, assim conhecida no Brasil, é o cacto Opuntia fícus-indica (OFI), uma planta tropical ou subtropical que se desenvolve de forma selvagem nas regiões áridas e semiáridas, devido aos seus mecanismos de se adaptar a estes ambientes e de possuir elevada capacidade de biomassa, e que a proporciona crescer em condições adversas, como altas temperaturas, solos podres em nutrientes e terrenos desidratados (SOUZA, 2019).

A palma forrageira é suculenta, ramificada e arbustiva, seu tamanho varia, podendo alcançar até quatro metros de altura. Trata-se de uma planta formada por raízes e caules carnudos. O sistema radicular da OFI é superficial, possuindo uma distribuição horizontal que desenvolve características xeromórficas, permitindo sua sobrevivência a períodos prolongados de seca (MARTINS, 2011).

O uso do cacto Opuntia Ficus-Idica em materiais de construção é uma prática antiga. Já eram conhecidos seus benefícios para o setor da construção civil há pelo menos 2000 anos. Os indícios mais antigos da utilização do OFI foram descobertos em escavações arqueológicas que remontam aos primeiros habitantes mexicanos. Nas escavações foram encontradas sementes, cascas e fibras fossilizadas, com aproximadamente sete mil anos (SAENZ et al., 2006 apud SOUZA, 2019).

Segundo Monteiro (2015), apud, Oliveira (2018), para pastas e argamassas, a MOFI utilizada como um aditivo, aprimorou a trabalhabilidade e a resistência desses materiais construtivos, destacando-se que a MOFI se trata de um aditivo orgânico, natural e de baixo custo.

Dessa forma, mesmo sendo utilizada há séculos, existem poucos estudos voltados a aplicação específica da MOFI como aditivo natural em materiais cimentícios. Avaliações sistemáticas e efetivas que mensure as ações deste aditivo em estruturas variadas da construção civil tornam-se significativas. A literatura atual mostra que a composição química do cacto varia em função das condições de plantio, sazonalidade, clima, idade da planta e outros fatores. Assim sendo, torna-se importante conhecer e analisar os compostos mais ativos da MOFI quando utilizada como aditivo, permitindo então uma ampliação da literatura atualmente disponível (SOUZA, 2019).

\section{METODOLOGIA}


O método utilizado para realização deste trabalho foi baseado na pesquisa experimental. Foram produzidos quatro tipos de concretos a serem submetidos aos ensaios de resistência à compressão axial, absorção de água por capilaridade e peso específico conforme as normalizações brasileiras vingentes, foram estes: quatro corpos de prova de referência (sem adição da MOFI), outros doze nomeados de: MOFI 0,5\%; MOFI 1,0\% e MOFI 1,5\%, respectivamente com adições nas proporções de $0,5 \% ; 1,0 \%$ e $1,5 \%$ da MOFI com relação ao total de massa de cimento dos mesmos. Além disso, foram realizados ensaios de caracterização física dos agregados para obtenção do traço a ser seguido para confecção dos corpos de prova de concreto.

Os materiais utilizados para realização dos experimentos laboratoriais foram adquiridos em lojas de materiais de construção (no caso do cimento e brita), na Companhia de Água e Esgostos do Rio Grande do Norte - CAERN, (para obtenção da água que foi utilizada para o amassamento do concreto) e na zona rural do município de São José do Sabugí, interior do estado da paraíba, localidade de onde foram retirados os cactos para gerar o MOFI e a areia utilizada na confecção dos corpos de prova de concreto.

Foi utilizado o cimento Portland do tipo CP IV-32-RS da empresa Apodi ${ }^{\circledR}$, escolhido em virtude das suas indicações de uso, que são: para ambientes quimicamente agressivos; agregados reativos e concretagem de peças de grandes volumes, como é o caso da estrutura de contenção do tipo muro de arrimo por gravidade. Utilizou-se como agregado miúdo a areia natural de rio lavada, material adquirido no sítio Carnaubinha, zona rural do município de São José do Sabugí, situado na região do Seridó Ocidental, no estado da Paraíba. Antes de ser utilizada foi submetida ao peneiramento em malha $4,8 \mathrm{~mm}$ com a finalidade de se obter apenas a fração miúda da areia. Utilizou-se como agregado graúdo brita de origem granítica, obtida em uma loja de material de construção no município de Pau dos Ferros, região do Alto Oeste no estado do Rio Grande do Norte, a brita foi originária da própria região, e trata-se de brita tipo 1 (diâmetro característico máximo igual a $19 \mathrm{~mm}$ ). A água utilizada foi a proveniente da rede de distribuição que abastece a UFERSA campus Pau dos Ferros, a mesma se encontrava a temperatura ambiente.

Todos os ensaios e procedimentos experimentais desta pesquisa foram realizados no laboratório do curso de Engenharia Civil da Universidade Federal Rural do Semi-Árido (UFERSA), Campus Multidisciplinar de Pau dos Ferros-RN (CMPF). Inicialmente produziu-se os corpos de prova de concreto, realizou-se a cura ao ar por um período de 24 horas para os corpos de prova isentos da MOFI, e 48 horas para os corpos de prova com adição da MOFI, seguida da desmoldagem e consecutiva cura úmida, submersos em água por um período de 28 dias. Atingidos os 28 dias após a moldagem, e em cura úmida, os corpos-de-prova foram postos a temperatura ambiente para a obtenção da constância de suas massas.

O aditivo produzido sob a forma de pó, foi gerado a partir da utilização da palma forrageira. O mesmo foi elaborado pelo procedimento de mucilagem em pó, conforme mencionado no trabalho de Costa (2014). Os cactos do gênero Opuntia fícus indica foram extraídos do Sítio Carnaubinha, zona rural do município de São José do Sabugí-PB (Figura 4).

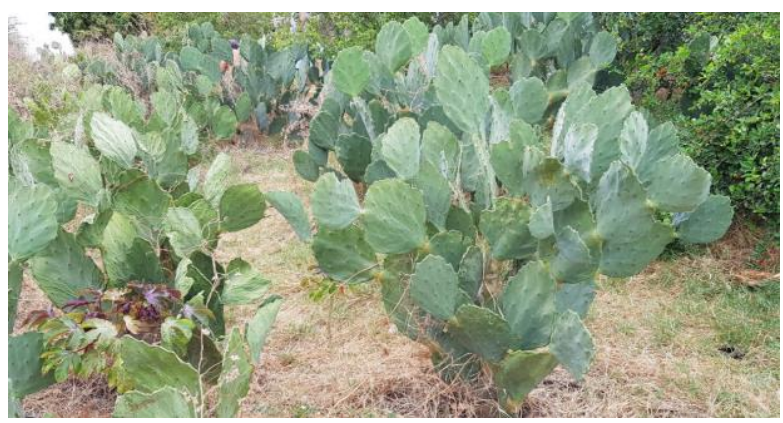

Figura 4: Cacto do gênero Opuntia em São José do Sabugí-PB

Fonte: os autores, 2019.

A caracterização física da areia utilizada para confecção do concreto desta pesquisa, foi realizada mediante ensaios de determinação da massa específica por meio do frasco de Chapman, determinação da massa unitária em estado solto e granulometria do agregado. Seguiu-se as instruções normativas dispostas em: NBR 9776:1987, NBR 7251:1982 e NBR7217:2003, respectivamente. 
A caracterização física da brita utilizada, foi desenvolvida mediante ensaios de determinação da massa específica, massa específica aparente e absorção de água do agregado graúdo; determinação da massa unitária compactada em estado solto e granulometria do agregado. Os ensaios realizados seguiram os procedimentos das normas: NBR NM 53:2003, NBR NM 45:2006 e NBR 7217:2003, respectivamente.

Com a caracterização física dos agregados miúdo e graúdo, bem como as propriedades físicas do cimento utilizados para confecção dos concretos dessa pesquisa, foi possível realizar os cálculos de dosagem de concreto pelo método de dosagem da Associação Brasileira de Cimento Portland - ABCP. O traço em massa obtido foi $1: 3: 2$ 1²: $0,6$.

A produção do aditivo de cacto em pó se deu através do processo da mucilagem, envolvendo diversas etapas. Foi utilizado, aproximadamente, $12 \mathrm{~kg}$ de cacto. Após pesadas e separadas as raquetes do cacto, as mesmas foram cortadas em pequenos pedaços. Em seguida colocou-se as bandejas com os pedaços cortados da palma forrageira na Estufa com Circulação e Renovação de Ar para desidratação à $105 \pm 5^{\circ} \mathrm{C}$ por aproximadamente 48 horas ininterruptas, essa etapa do procedimento pode ser vista na Figura 5.

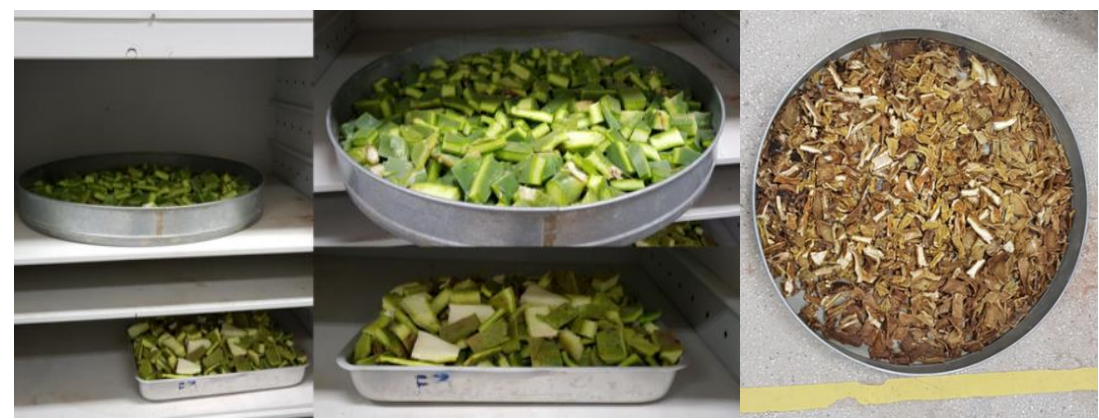

Figura 5: Processo de desidrtação da Palma Forrageira

Fonte: os autores, 2019.

Após retirados os cactos da Estufa, reservou-os para retornar a temperatura ambiente. Em seguida triturou-se o cacto desidratado no liqudificador e e peneirou-se o material obtido na peneira de abertura $600 \mu \mathrm{m}$, conforme ilustra a Figura 6. Após o peneiramento da Mucilagem do cacto Opuntia Ficus Indica - MOFI, obteve-se 1214,2 g do aditivo.

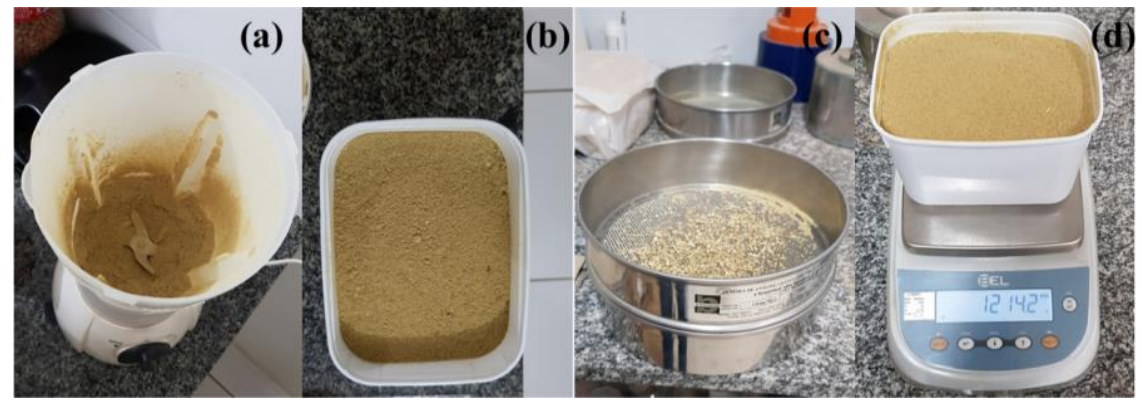

Figura 6: MOFI - (a) triturando, (b) volume total do cacto triturado, (c) peneiramento da MOFI e (d) MOFI finalizado Fonte: os autores, 2019.

Após a moldagem e cura úmida dos CP's, foram reservados por 24 horas para secagem sob temperatura ambiente. Depois de secos, realizou-se pesagens de todos os corpos de prova confeccionados para posterior determinação de seus pesos específicos. O ensaio de absorção de água por capilaridade no concreto foi realizado conforme especificações da ABNT NBR 9779:2012 - Argamassa e concreto endurecidos: Determinação da absorção de água por capilaridade. Todos os CP's produzidos foram submetidos ao ensaio. O ensaio de compressão axial foi realizado para todos os CP's conforme especificações normativas da NBR 5739:1994 - Concreto - Ensaio de compressão de corpos-de-prova cilíndricos, numa prensa elétrica digital (teste de compreensão).

\section{RESULTADOS E DISCUSSÃO}

Os resultados obtidos na fase de caracterização física do agregado miúdo se encontram dentro das médias apresentadas nas bibliografias que tratam do assunto, com exceção do módulo de finura obtido a partir do ensaio de granulometria, 
que apresentou um valor superior ao maior valor mencionado na NBR 7211:2005. A Tabela 1 informa os valores obtidos.

Tabela 1 - Resultados da caracterização física da areia

\begin{tabular}{c|c}
\hline Característica & Valor encontrado \\
\hline Massa específica & $2,53 \mathrm{~g} / \mathrm{cm}^{3}$ \\
\hline Massa unitária solta & $1,43 \mathrm{~g} / \mathrm{cm}^{3}$ \\
\hline Módulo de finura (granulometria) & 4,36 \\
\hline
\end{tabular}

Fonte: os autores, 2019.

Os resultados obtidos na fase de caracterização física do agregado graúdo também se encontraram dentro das médias apresentadas nas bibliografias. Os valores obtidos podem ser observados na Tabela 2.

Tabela 2 - Resultados da caracterização física da brita

\begin{tabular}{c|c}
\hline Característica & Valor encontrado \\
\hline massa específica do agregado seco & $3,0 \mathrm{~g} / \mathrm{cm}^{3}$ \\
\hline Massa específica aparente & $3,2 \mathrm{~g} / \mathrm{cm}^{3}$ \\
\hline Massa unitária compactada & $1,4 \mathrm{~g} / \mathrm{cm}^{3}$ \\
\hline Absorção de água & $1,73 \%$ \\
\hline
\end{tabular}

Fonte: os autores, 2019.

A partir do conhecimento da massa e do volume dos corpos de provas produzidos, foi possível obter seus pesos específicos, já que para efeitos práticos o peso específico de um material trata-se da relação (divisão) da sua massa pelo seu volume (BOTELHO E MARCHETTI, 2004). A Figura 7 ilustra o comportamento da variação dos resultados.

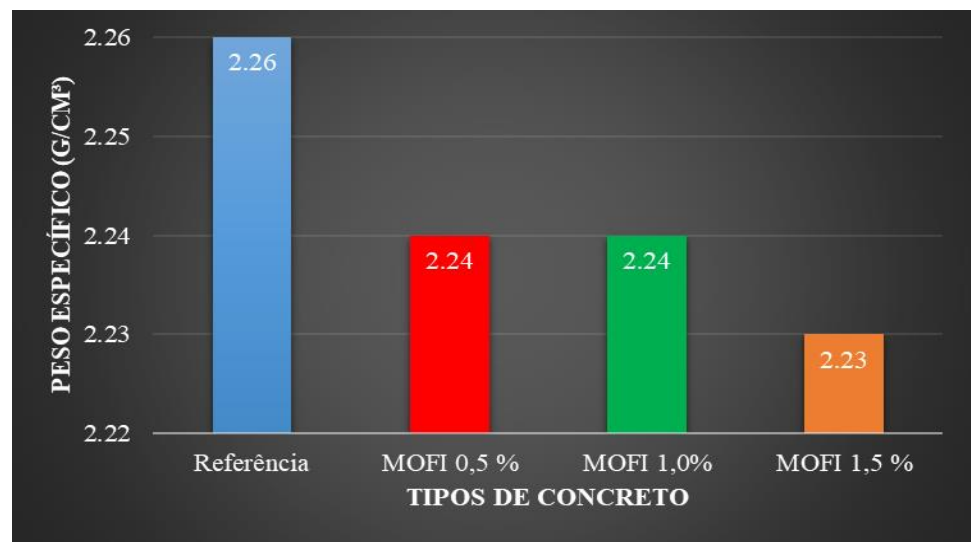

Figura 7: Peso específico dos concretos em função do tipo Fonte: os autores, 2019.

O maior valor de peso específico encontrado foi para o concreto de referência, ou seja, para o concreto isento do aditivo do cacto em pó. Todos os concretos com adição da mucilagem da palma forrageira tiveram valores de peso específico menores em comparação ao concreto de referência, nos quais estes, obtiveram valores bem próximos, entre $2,23 \mathrm{~g} / \mathrm{cm}^{3} \mathrm{e}$ $2,4 \mathrm{~g} / \mathrm{cm}^{3}$.

Analisando a viabilidade em termos de peso específico, os concretos com adição da MOFI não seriam os mais indicados para utilização em estruturas de contenção do tipo muro de arrimo por gravidade, já que sua principal característica é o seu peso próprio. Neste caso, o mais eficaz em termos de peso específico seria o isento de adição da MOFI, embora como a diferença foi muito pequena, não impossibilitaria a utilização dos concretos aditivados.

As absorções de água por capilaridade nos concretos foram calculadas seguindo o posto na NBR 9779:2012. Para cada intervalo de tempo na qual se realizou pesagens da massa saturada dos CP's, foi encontrado o valor médio de absorção por tipo de concreto produzido, conforme informa a Tabela 3 . 
Tabela 3 - Valores da absorção média da água por capilaridade

\begin{tabular}{c|c|c|c|c|c}
\hline \multirow{2}{*}{ Tipo de concreto } & \multicolumn{5}{|c}{ Absorção $\left(\mathbf{g} / \mathbf{c m}^{2}\right)$} \\
\cline { 2 - 6 } & $3 \mathrm{~h}$ & $6 \mathrm{~h}$ & $24 \mathrm{~h}$ & $48 \mathrm{~h}$ & $72 \mathrm{~h}$ \\
\hline Referência & 0.24 & 0.21 & 0.22 & 0.16 & 0.11 \\
\hline MOFI 0,5 \% & 0.23 & 0.23 & 0.20 & 0.14 & 0.08 \\
\hline MOFI 1,0 \% & 0.23 & 0.23 & 0.20 & 0.13 & 0.08 \\
\hline MOFI 1,5 \% & 0.23 & 0.23 & 0.19 & 0.14 & 0.10 \\
\hline
\end{tabular}

Fonte: os autores, 2019.

Conforme observa-se nos resultados obtidos para o ensaio de absorção de água por capilaridade nos concretos, houve um comportamento atípico na tendência dos resultados, pois, diferente do comumente visto nas literaturas, a absorção em todos os concretos produzidos foi decrescendo com o passar do tempo. A Figura 8 ilustra melhor esse comportamento.

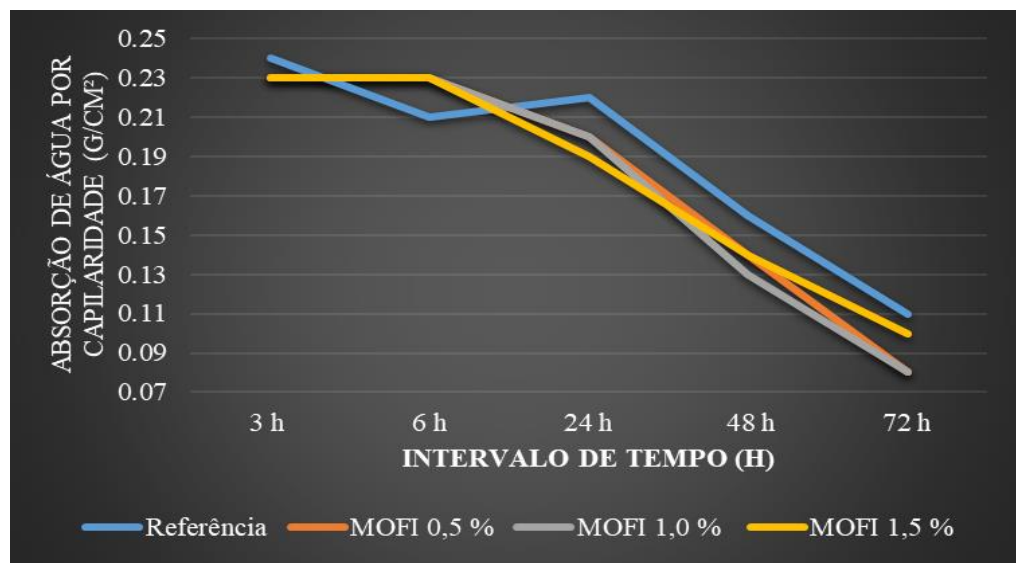

Figura 8: Comportamento do ensaio de absorção média de água por capilaridade em função do tempo Fonte: os autores, 2019.

Percebe-se que o concreto de referência, isento do aditivo em pó, ao passar 3 horas em contanto com a água, obtém sua absorção máxima, decaindo bruscamente na medição de 6 horas, voltando a absorver após decorridas 24 horas do ensaio, e decaindo gradativamente no restante do tempo.

Já para os três tipos de concreto aditivados com $0,5 \% ; 1,0 \%$ e 1,5\% da MOFI entre 3 h e 6 h em contato com a água se mantiveram com um valor de absorção constante e máximo, e no restante do tempo foram absorvendo menos, havendo um comportamento também de ascensão após as 6 primeiras horas de ensaio.

Diversos fatores podem ter influenciado nos resultados atípicos obtidos neste ensaio, como a imprecisão dos equipamentos, visto que a medição do nível de água foi realizada de forma manual com auxílio de uma régua, por falta de equipamento específico no laboratório de Engenharia Civil da UFERSA CMPF, na qual essa medição seria realizada de forma automática assim como a reposição da água necessária. Assim como o aparato utilizado para evitar que os CP's tocassem o fundo do recipiente utilizado no ensaio, que foi um improviso com uma tela metálica.

A falta de controle da temperatura no ambiente também ter manipulado os resultados do ensaio. Outra questão a se levar em consideração trata-se da utilização de óleos no molde dos CP's no momento da moldagem com a finalidade de facilitar a desmoldagem, haja visto a falta de desmoldante para concretos, tanto nos materiais do laboratório utilizado, quanto no comércio de Pau dos Ferros, então foi utilizado óleo de motor, e mesmo com a cura úmida do concreto por 28 dias ainda pôde-se perceber indícios desse material aderido as superfícies dos CP's o que pode ter dificultado a ascensão capilar da água durante o ensaio, uma vez que a própria NBR 9779:2012 sugere que os concretos estejam isentos de óleos.

Dessa forma, o melhor resultado para as estruturas de contenção do tipo muro de arrimo por gravidade, seria o concreto com obtenção da maior taxa de absorção de água, pois, quanto mais absorvente o material, mais permeável seria, e consequentemente poderia dispensar a execução de elementos drenantes na estrutura, que são onerosos. Com a 
atipicidade nos resultados fica incompreensível averiguar qual dos tipos de concretos produzidos nesta pesquisa seria o mais viável nesse aspecto.

Os valores obtidos no ensaio de resistência a compressão axial dos concretos foram maiores que os predefinidos para obtenção do traço utilizado para confecção dos concretos, de $20 \mathrm{Mpa}$. Os concretos mais resistentes foram o aditivado em $1 \%$ com o Mucilagem do cacto em pó e o de referência, respectivamente.

Então, percebe-se que a utilização do aditivo produzido a partir da Palma Forrageira potencializou a característica mecânica de resistência a compressão do concreto, resultado este já esperado tendo em vista as propriedades do cacto já mencionadas anteriormente neste trabalho. A Figura 9 ilustra os resultados das resistências médias obtidas.

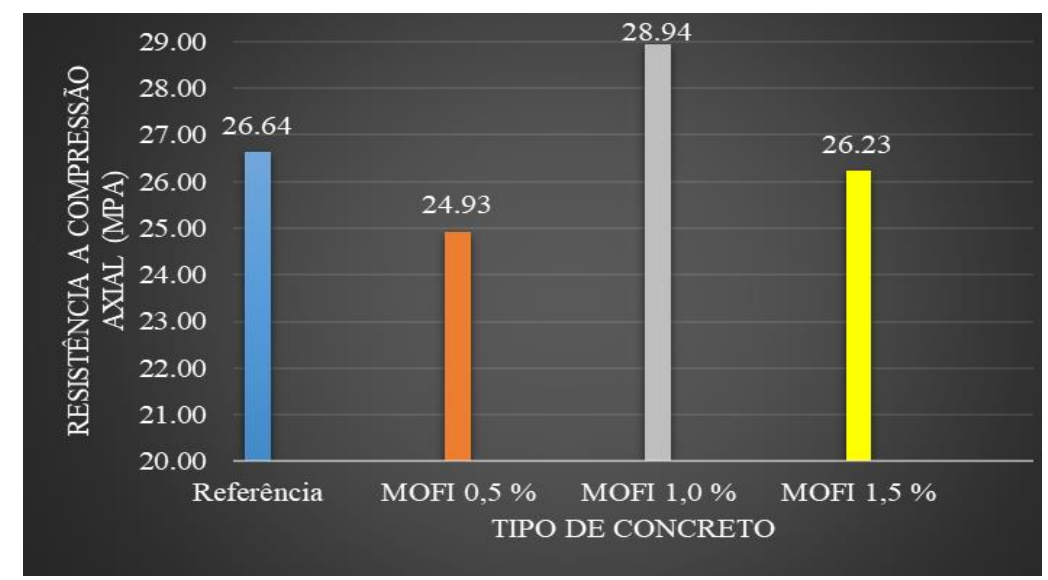

Figura 9: Resistência média a compressão dos concretos

Fonte:os autores, 2019.

O concreto com maior resistência média a compressão foi o com a utilização de 1,0 \% da MOFI, que obteve um ganho de resistência de quase $9 \%$ em relação ao concreto sem adição, conforme visualiza-se no gráfico da Figura 39 . Na sequência os concretos mais resistentes foram o de Referência, com adição de 1,5\% e por último com adição de $0,5 \%$.

Dessa maneira, o teor do aditivo da palma forrageira proveniente da sua mucilagem com eficiência para melhorar a propriedade de resistência do concreto trata-se de 1,0\%. Vale ressaltar que outros teores chegaram a ser inicialmente verificados nesta pesquisa, foram estes: 3,0 \% e 4,5\% da MOFI, porém, percebeu-se que quando o concreto foi aditivado nessas proporções mais próximas do limite máximo imposto na norma de aditivos para concretos, o concreto não endureceu, após 72 horas ainda se encontrava em estado semifluido, o que inviabilizou a continuidade da pesquisa fazendo uso dessas quantidades do aditivo, e procedeu-se utilizando teores de $0,5 \% ; 1,0 \%$ e $1,5 \%$.

\section{CONSIDERAÇÕES FINAIS}

Com a realização dos ensaios de peso específico, absorção de água por capilaridade e resistência a compressão axial nos concretos produzidos neste trabalho, fica consumado a viabilidade parcial da adição de Mucilagem do cacto "Opuntia Ficus Indica" em concretos para estruturas de contenção do tipo muro de arrimo por gravidade. O aditivo em pó não se mostrou totalmente viável para esse tipo de estrutura, visto que diminuiu o peso específico do concreto e sua taxa de absorção foi inconclusiva, tendo um resultado positivo, portanto, apenas no que diz respeito a melhoria da resistência a compressão.

Foi possível averiguar com essa pesquisa a incorporação adequada a ser utilizada da MOFI para gerar efeitos positivos ao concreto, que se trata da adição em 1,0\%. Chegou-se a essa conclusão, pois foi para essa quantidade de aditivo em pó incorporado ao concreto, que os resultados no ensaio de compressão axial dos corpos de prova, foram superiores ao do concreto isento de adição e aos aditivados em $0,5 \%$ e 1,5\%. Além de terem sido testadas outras proporções do aditivo anteriormente, que foram inconvenientes por modificar de forma brusca as características do concreto, mostrando que o aditivo não deve ser utilizado em quantidades inferiores e nem superiores a 1,0\% pelos resultados aqui obtidos. 
Analisando os pesos específicos dos concretos confeccionados, percebe-se que o concreto com maior peso específico foi o de referência, ou seja, para produção de muros de arrimo por gravidade, no qual sua primordial característica tratase do peso próprio da estrutura, os concretos com adições do aditivo do cacto em pó não seriam os mais indicados. O que não dispensa a utilização do aditivo em concretos para confecção de outros tipos de estruturas, onde concretos mais leves seriam necessários, para reduzir o peso da estrutura.

Avaliando a absorção dos concretos produzidos, foi notório uma atipicidade no ensaio de absorção de água por capilaridade, onde diversos fatores podem ter influenciado o ensaio, como temperatura e imprecisão dos equipamentos utilizados. Diferente do comumente abordado nas literaturas, o resultado esperado era que a absorção fosse crescendo, mesmo que mais em alguns corpos de provas do que em outros, porém o que ocorreu foi uma máxima absorção entre as 3 horas e as 6 horas iniciais do ensaio, e uma redução de absorção durante o restante do tempo, dessa forma fica inviável concluir qual seria o concreto mais viável para confecção de muros de arrimo por gravidade.

Verificando a resistência a compressão dos concretos, a incorporação da MOFI age de forma positiva, uma vez que a resistência média obtida no ensaio de compressão axial para o concreto com adição de 1,0 \% do cacto em pó foi superior em aproximadamente $9 \%$ a resistência do concreto isento da incorporação da mucilagem da Palma Forrageira.

A realização de pesquisas futuras para outras estruturas com a incorporação da MOFI, e a produção do aditivo por outros procedimentos, como a extração da Mucilagem em líquido, para comparar com os resultados aqui encontrados, onde talvez o líquido preserve mais as características da planta do que a desidratação realizada neste trabalho, seria algo pertinente a se avaliar. Espera-se que os resultados obtidos sirvam de base para outros pesquisadores em busca de novos materiais que possam enriquecer os componentes da cadeia produtiva da construção civil.

\section{REFERÊNCIAS}
ALMEIDA,
L. C.
Concreto.
UNICAMP,
2002.
Disponível
em:

http://www.fec.unicamp.br/ almeida/au405/Concreto.pdf. Acesso em: 22 set. 2019.

AMBROZEWICZ, P. H. L. Materiais de construção: normas, especificações, aplicação e ensaios de laboratório. São Paulo. Ed Pini. 2012.

AMERICAN CONCRETE INSTITUTE ACI. “Cement and Concrete Terminology". ACI 318 Farmington Hills, 2005 .

ANDRADE, A. C. O. T. DANTAS, E. S. DIAS, L. K. L. ARAÚJO, M. E. P. SILVA, M. J. Geotécnica: fundações e obras de terra. Cadernos de Graduação - Ciências Exatas e Tecnológicas. Sergipe, v. 1. n.16. p. 27-43. 2013.

ARAÚJO, P. S. C. Desenvolvimento de ferramenta computacional para dimensionamento de muros de arrimo. Araruna, 2016.

ASSOCIAÇÃO BRASILEIRA DE NORMAS TÉCNICAS. NBR 11768: Aditivos para Concreto de Cimento Portland requisitos. Rio de Janeiro, 2011.

ASSOCIAÇÃO BRASILEIRA DE NORMAS TÉCNICAS. NBR 16697: Cimento Portland: Requisitos. Rio de Janeiro, 2018.

ASSOCIAÇÃO BRASILEIRA DE NORMAS TÉCNICAS. NBR 5739: Concreto - Ensaio de compressão de corposde-prova cilíndricos. Rio de Janeiro, 1994.

ASSOCIAÇÃO BRASILEIRA DE NORMAS TÉCNICAS. NBR 6118: Projeto de estruturas de concreto Procedimento. Rio de Janeiro, 2014.

ASSOCIAÇÃO BRASILEIRA DE NORMAS TÉCNICAS. NBR 7211: Agregado para concreto - Especificações. Rio de Janeiro, 2005.

ASSOCIAÇÃO BRASILEIRA DE NORMAS TÉCNICAS. NBR 7217: Agregados - Determinação da composição granulométrica. Rio de Janeiro, 2003. 
ASSOCIAÇÃO BRASILEIRA DE NORMAS TÉCNICAS. NBR 7251: Agregado em estado solto - Determinação da massa unitária. Rio de Janeiro, 1987.

ASSOCIAÇÃO BRASILEIRA DE NORMAS TÉCNICAS. NBR 8953: Concreto para fins estruturais classificação pela massa específica, por grupos de resistências e consistência. Rio de Janeiro, 2015.

ASSOCIAÇÃO BRASILEIRA DE NORMAS TÉCNICAS. NBR 9776: Agregados - Determinação da massa específica de agregados miúdos por meio do frasco chapman - Método de ensaio. Rio de Janeiro, 1987.

ASSOCIAÇÃO BRASILEIRA DE NORMAS TÉCNICAS. NBR 9779: Argamassa e concreto endurecidos Determinação da absorção de água por capilaridade. Rio de Janeiro, 2012.

ASSOCIAÇÃO BRASILEIRA DE NORMAS TÉCNICAS. NBR NM 45: Agregados - Determinação da massa unitária e do volume de vazios. Rio de Janeiro, 2006.

ASSOCIAÇÃO BRASILEIRA DE NORMAS TÉCNICAS. NBR NM 53: Agregado graúdo - Determinação de massa específica, massa específica aparente e absorção de água. Rio de Janeiro, 2003.

BOTELHO, M. H. C.; MARCHETTI, O. Concreto armado eu te amo. São Paulo: Edgard Blucher, 2004.

CABRAL, S.C. AZEVEDO, M. A. Materiais alternativos para adição ao cimento Portland. Minas Gerais, Revista

Científica Vozes dos Vales, $\mathrm{N}^{\circ}$. $10-$ Ano V $-10,2016$. Disponível em: http://site.ufvjm.edu.br/revistamultidisciplinar/files/2016/09/Stenio23.pdf. Acesso em 18 set. 2019.

COSTA, A. C. S. S. Utilização de aditivos à base de cacto em argamassa de cimento portland. Mossoró-RN, 2014. DEPARTAMENTO DE ESTRADAS DE RODAGEM - DER. Projeto de muro de arrimo. IP-DE-C00/005. 2005.

GERSCOVICH, D. M. S. Estruturas de Contenção-Muros de Arrimo. Disponível em: http://www.eng.uerj.br/ denise/pdf/muros.pdf . Acesso em: 28 set. 2019.

JÚNIOR, T. F. S. Estruturas de concreto armado. S.A. Disponível em: https://docente.ifrn.edu.br/valtencirgomes/disciplinas/construcao-de-edificios/apostila-concreto. Acesso em: 22 set. 2019.

KNAPPETT, J.A. CRAIG, R.F. Craig mecânica dos solos. Tradução: Amir Elias Abdalla Kurban. 8 ed. [Reimpr.]. Rio de Janeiro: LTC, 2016. 419 páginas.

MARTINS, S. C. C. Avaliação do potencial biológico de Opuntia ficus-indica (Figueira da Índia). 2011. Faculdade de Ciências da Saúde, 2011.

MATERA, D. R. e ROMANEL, C. Estabilidade de Muros de Gravidade. Rio de Janeiro, 2014. Disponível em: http://www.pucrio.br/pibic/relatorio_resumo2014/relatorios_pdf/ctc/CIV/CIVDouglas\%20Rocha\%20Matera.pdf.

Acesso em: 18 set. 2019.

NEVILLE, A. M. e BROOKS, J. J. Tecnologia do concreto. Tradução: Ruy Alberto Cremonini. 2 ed. Porto Alegre, Brookman, 2013. 448 páginas.

OLIVEIRA, H. C. M. Incorporação da mucilagem de palma forrageira na elaboração de argamassa cimento Portland. Areia-PB, 2018.

SOUZA, G. F. A.; CAPUZZO, V. M. S.; SILVA, F. M.; AZEVEDO, C. A.; NOGUEIRA, J. V. A.; Avaliação da utilização de aditivo biopolimérico a base de Opuntia fícus indica em materiais cimentícios. IBRACON, ISSN 2175-8182. 2018.

VARELA, M. Instituto Federal de Educação, ciência e tecnologia do Rio Grande. Curso tecnologia da construção civil, disciplina de estruturas de contenção.

VIVA DECORA. Muro de Arrimo: Preserve o Seu Terreno com Beleza e Segurança. 2019. Disponível em: https://www.vivadecora.com.br/revista/muro-de-arrimo/ . Acesso em: 28 set. 2019. 